\title{
Papila Apical Dentaria como fuente de Células Madre: Relato del Caso
}

\author{
Ivelyze Ivelyze de Souza Amaral Bernini, ${ }^{1}$ \\ Rafaela Cavalcanti Amaral, ${ }^{2}$ \\ José Carlos P. Imparato, ${ }^{3}$ \\ Karla Mayra Rezende. ${ }^{4}$
}

\section{Resumen}

Las células madre mesenquimales (MSCs) son células madre adultas que tienen la capacidad de diferenciarse en varios tipos de células. Una rica fuente de células madre mesenquimales puede ser obtenida de tejidos dentales como la papila apical. El objetivo de este trabajo fue extraer las células madre de la papila apical de terceros molares humano para mirar su viabilidad de usarse en la práctica clínica. La de separación celular con Stro1 y estudio de cinéticas fueron realizados. Como resultado, esas células, presentaron alta tasa de proliferación, formación de colonias y fácil acceso. Concluimos que el uso de células madre obtenidas de diente puede ser una buena alternativa por ser de fácil acceso, alta viabilidad celular y expresión positiva para marcadores celulares mesenquimales. La regeneración tisular o la formación de estructuras craneofaciales constituyen el futuro de la medicina regenerativa, ofreciendo una posibilidad para el tratamiento de malformaciones congénitas, traumas y otras enfermedades.

Palabras clave: Células madres; odontopedíatria, regeneración tisular.

Caso clinico

\section{Papila Apical Dentária como Fonte de Células Tronco: Relato de Caso}

\section{Resumo}

As células tronco mesenquimais (CTMs) são células-tronco adultas que têm a capacidade de diferenciar em vários tipos de células. Uma rica fonte de células tronco mesenquimais pode ser obtida de tecidos dentais como a papila apical. O objetivo deste trabalho foi extrair as células tronco da papila apical de terceiros molares humano para ver sua viabilidade de ser usado na prática clinica. Teste separação

${ }^{1}$ Mestranda en Odontopediatria - São Leopoldo Mandic, São Paulo, Brazil.

2Doutoranda em Odontopediatria, Faculdade São Leopoldo Mandic, São Paulo, Brazil.

${ }^{3}$ Profesor Libre Docente Odontopediatria - FOUSP - Profesor Dr. Libre docente Odontopediatria- FOUSP Professor Curso Especialización en Odontopediatría - FFO USP Coordenador del Curso de Postgrado en Odontopediatría São Leopoldo Mandic, São Paulo, Brazil.

${ }^{4} \mathrm{PhD}$ Odontopediatria-FOUSP, Profesora Postgrado em Odontopediatria São Leopoldo Mandic, FFO-USP, Unimes, São Paulo, Brazil. 
celular com Stro-1 e estudo de cinéticas foram realizados. Como resultado essas células apresentaram alta taxa de proliferação, formação de colônias e de fácil acesso. Concluímos que o uso de células tronco obtidas de dente pode ser uma boa alternativa por ser fácil acesso, alta viabilidade celular e expressão positiva para marcadores celulares mesenquimais.
A regeneração tecidual ou a formação de novo de estruturas craniofaciais é o futuro da medicina regenerativa, oferecendo uma possibilidade para tratamento de malformações congênitas, traumas e outras doenças.

Palavras chaves: Células tronco, odontopediatria, regeneração tecidual.

Case report

\section{Dental Apical Papila Stem Cell: Case Report}

\begin{abstract}
Mesenchymal stem cells (MSCs) are adult stem cells that have the ability to differentiate into various cell types. A rich source of mesenchymal stem cells can be obtained from dental tissues such as the apical papilla. The objective of this work was to extract stem cells from the apical papilla of third human molars to see its feasibility to be used in clinical practice. Testing of cell separation with Stro-1 and study of kinetics were performed. As a result, these cells had a high rate of pro-
\end{abstract}

\section{Introducción}

Las células madre adultas, son células indiferenciadas presentes, mínimamente en el cuerpo después del nacimiento. Ellas tienen como función hacer la homeostasis tisular, para eso pueden proliferarse y diferenciarse, en células diferentes de su origen, y así, la capacidad de generar renovación celular. ${ }^{1,2}$ A nivel experimental, se observó que las células madre pueden regenerar órganos o partes de un tejido dañado, por eso tienen enorme potencial en el tratamiento de diversas enfermedades. ${ }^{3}$ liferation, formation of colonies and easy access. We conclude that the use of stem cells obtained from teeth can be a good alternative because they are easy to access, high cell viability and positive expression for mesenchymal cell markers. Tissue regeneration or new formation of craniofacial structures is the future of regenerative medicine, offering a possibility for treatment of congenital malformations, traumas and other diseases.

Key words: Apical papilla, pediatric dentistry, tissue regeneration.

El descubrimiento de células madre dentales comenzó con el equipo de investigadores liderados por Gronthos ${ }^{4}$ en el año 2000, cuando al aislar las células de la pulpa dental de dientes permanentes, estas presentaron células indiferenciadas con las características de las células tronco obtenidas de la médula ósea, con todas las características altamente proliferativas, clonogénicas y con potencialidad de generar diferentes tejidos. ${ }^{5}$

En la odontología las principales fuentes de células madre son el folículo dental, 
la pulpa dental de dientes deciduos y permanentes, el ligamento periodontal y la papila apical. ${ }^{6,7}$

La papila apical contribuye en la formación de la raíz dentaria. Tiene como función biológica la formación de la dentina y pulpa radicular actuando también en la remodelación de la forma de la corona del futuro diente..$^{8-10}$ Actualmente, las células madre de la papila apical representan una nueva población de células madre multipotentes con capacidad de distinguirse en odontoblastos y adipocitos, expresar altos niveles de survivina y telomerasa (proteína y enzima que tiene como función primordial la proliferación y supervivencia celular). ${ }^{11,12}$

El objetivo de este trabajo es estudiar la posibilidad de aislar células madre de la papila dentaria para que sea un tejido para estudio de caracterización y ser una fuente, en el futuro, para tratamiento regenerativo.

\section{Relato del caso}

Paciente, 23 años, género femenino, sin antecedentes de enfermedades sistémicas o alergias, compareció a la clínica odontológica con planificación para cirugía de los dientes 28 y 48 . El procedimiento quirúrgico fue realizado en la clínica odontológica de la Facultad de Odontología de la Universidad de São Paulo (FOUSP) después de la aprobación del Comité de Ética y Pesquisa de esta Universidad y firma del Término de Consentimiento Libre y Aclarado del paciente.

Inmediatamente después de la cirugía, el diente envuelto en el capuchón pericoronario fue almacenado en el medio de transporte compuesto por $3 \mathrm{~mL}$ $\alpha$ MEM (Minimum Essential Medium Eagle - $\alpha$ modification, Sigma $\left.{ }^{\circledR}\right)$ con $2 \%$ de solución antibiótica-antimicótica $\left(\mathrm{Gibco}^{\circledR}\right.$ Walthan, USA), y colocado en una caja de espuma de poliestireno con hielo y llevado al laboratorio de cultivo celular de la Asignatura de Patología Bucal donde todos los procedimientos de cultivo fueron realizados.

Todos los procedimientos experimentales fueron realizados por un investigador calificado en técnicas de cultivo celular (Figura 1). Para el inicio del procedimiento de cultivo primario, se lavó el diente 5 veces con PBS a 2\% de antibiótico y antimicótico (Sigma ${ }^{\circledR}$ St. Louis, USA). Primeramente, se retiró el capuchón pericoronario utilizando bisturí. Los tejidos fueron
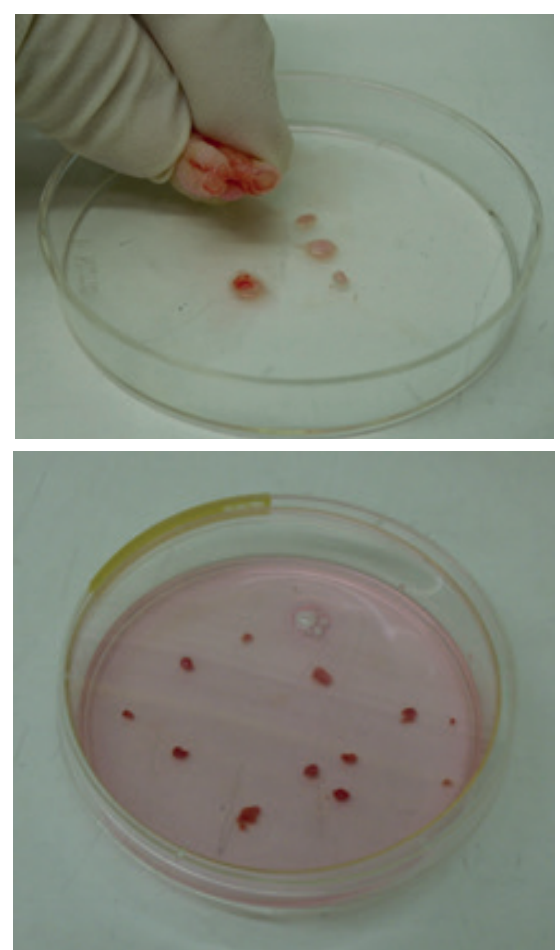

Figura 1. Diente con sus respectivos tejidos después de la extracción. Se observa el ápice abierto del tercer molar molar. 
fragmentados en trozos menores que $1 \mathrm{~mm}^{2}$ y colocados en placa Petri y monitoreados diariamente. Los explantes quedaron en el medio de cultivo de manutención que se constituía de $\alpha$ MEM (Minimum Essential Medium Eagle $-\alpha$ modification) con $1 \%$ de solución antibiótica-antimicótica, $1 \%$ $\beta$-mercaptoetanol y $10 \%$ de suero fetal bovino (FBS), $100 \mu \mathrm{M}$ de ácido ascórbico y 2 mM de L-Glutamina (Glutamax ${ }^{\circledR}$ Gibco).

Después que las células migraron y se adhirieron a la placa, el medio de cultivo fue sustituido, de acuerdo con la necesidad del metabolismo celular. El monitoreo del crecimiento celular fue realizado a través de microscopio invertido de fase y aspectos como vitalidad celular, coloración $\mathrm{y}$ aspecto del medio fueron analizados.

Después de alcanzar $75 \%$ de confluencia en la placa, las células fueron subcultivadas de acuerdo con la necesidad de nuevas placas. Para ese propósito, la mono camada celular es lavada con PBS, sin calcio y magnesio $(\mathrm{pH} 7,2)$ y las células fueron separadas con $2 \mathrm{~mL}$ de solución de tryple E (Invitrogen) en temperatura de $37^{\circ}$ C. Las células en suspensión fueron centrifugadas a $1500 \mathrm{rpm}$ por 5 minutos a temperatura ambiente. El precipitado celular fue resuspendido en medio de cultivo fresco, tanto para adquisición de alícuotas para nuevo crecimiento celular, como para congelamiento cuando fuese necesario.

\section{Aislamiento de las Células Madre por Medio de la Técnica De Macs (Magnetic- Activated Cell Sorting)}

Las células fueron expandidas hasta alcanzar el marco $1 \times 10^{7}$ luego se aislaron através del uso de magneto (MACS
R, Miltenyi Biotec), de acuerdo con las especificaciones del fabricante. El protocolo de la selección positiva consiste en realizar el marcado de la fracción de las células con anticuerpos conjugados a microesferas magnéticas. Así, cada linaje de la pulpa y papila serán separadas con siguientes marcadores: Stro-1. (Figura 2)

Para cada uno de los anticuerpos antes mencionados, el inicio, fue preparada una solución homogénea de células en suspensión. Para formar una solución de células aisladas, estas pasaron por un filtro de nylon $70 \mu \mathrm{m}$ de poro (BD FalconTM, ref. 352350), a fin de prevenir la obstrucción de la columna.

La cantidad de 107 células fueron transferidas para tubo Falcon de $15 \mathrm{ml}$, centrifugado a $1500 \mathrm{rpm}$ durante 10 minutos. El sobrenadante fue aspirado $\mathrm{y}$, posteriormente, las células fueron resuspendidas en $80 \mu \mathrm{l}$ en solución tampón, $10 \mu \mathrm{l}$ de bloqueador con

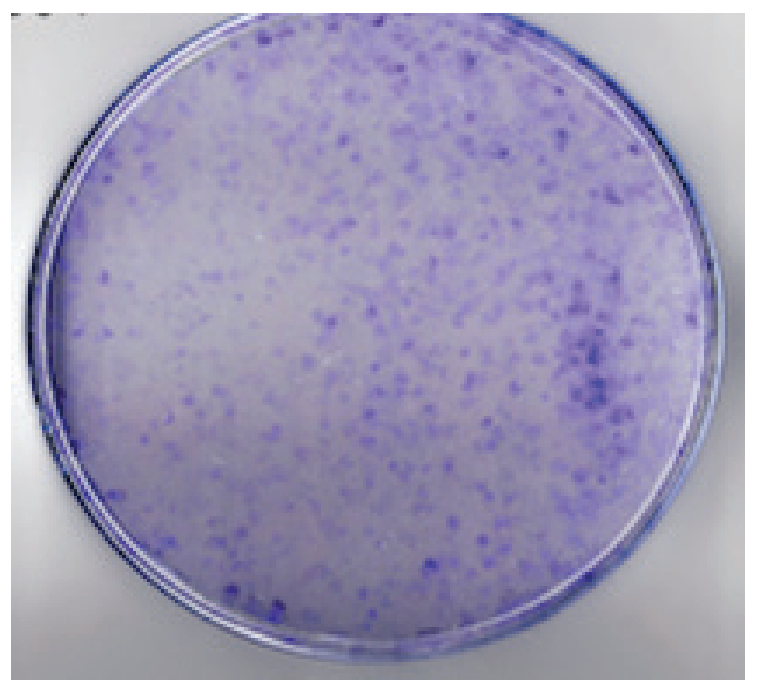

Figura 2. Placa de petri com revestimento de celulas para verificar y contar colônias celulares. 
$10 \mu \mathrm{l}$ del anticuerpo e incubadas durante una hora. Después de ese tiempo, la solución conteniendo células y reactivos fue homogeneizada bajo refrigeración durante 10 minutos $\mathrm{y}$, posteriormente, centrifugada a $1500 \mathrm{rpm}$ por 10 minutos.

El sobrenadante fue aspirado y las células fueron resuspendidas en $500 \mu \mathrm{l}$ de solución tampón al cual serán añadidos $10 \mu \mathrm{l}$ de bloqueador y $20 \mu \mathrm{l}$ de anticuerpo secundario asociado a microbeads de aislamiento. La solución conteniendo las células fue pasada a través de columna magnética, ya montada en el separador.

\section{Teste de Crecimiento Celular}

La cantidad de $1 \times 10^{4}$ células/ml fueron colocadas en placas de 12 pozos y después de 3, 6, 9 y 12 días estas fueron removidas de 3 pozos a cada vez (experimento en triplicado) por medio de la acción del reactivo TrypLETM (Gibco, \#12563) y contadas con cámara de Neubauer. Los datos fueron tabulados y calculados, el promedio del número y la desviación estándar.

Todos los experimentos de viabilidad fueron realizados por triplicado. Los resultados de los recuentos archivados, el promedio fue calculado y un gráfico comparando las varias poblaciones fue constituido.

\section{Ensayo de CF U-F (Colony Forming Unit - Fibroblast)}

Para el análisis de la capacidad de formación de colonias, 104 células fueron colocadas en placas de Petri de
$10 \mathrm{~cm}^{2}$ de diámetro. El cambio del medio era realizado cada 2 días. Después de un período de 8 días, las mismas fueron fijadas con metanol a $4^{\circ} \mathrm{C}$ y teñidas en solución de azul de toluidina a $0,5 \%$, por 5 minutos, posteriormente las colonias formadas fueron contadas. Se consideraron colonias, agregados celulares conteniendo más de 50 células. Las células fueron fotografiadas en aumento de 10 veces y las placas, escaneadas para análisis morfológico.

\section{Resultados}

El objetivo de este trabajo fue relatar y analizar la posibilidad de extraer células madre de la papila apical dentaria. Esas células fueron obtenidas de terceros molares que tenían indicación de exodoncia. La técnica de explant fue la elección para extracción, de las células presente, en el tejido de la papila apical.

Después del cultivo de las células los, ensayos funcionales fueron realizados. Para el aislamiento celular se realizó la técnica de explant. Luego de la separación de las células madre, con las células ya diferenciadas se realizaron 2 ensayos funcionales. El primero fue la curva de crecimiento. Después de la siembra, las células fueron contadas en 3, 6, 9 y 12 días de cultivo. Observamos que hubo un descenso de células en el noveno día de cultivo, pero a los 12 días hubo una recuperación de esas células (Tabla 1 ).

El ensayo de formación de colonias refleja directamente la competencia del crecimiento. Se consideró colonia, aglomerados de más de 50 células (Figura 3). 
Tabla 1. Desviación media y estárdar del crecimiento celular a los 3, 6, 9 y 12 días de cultivo.

\begin{tabular}{|l|c|c|c|c|}
\hline Días & 3 & 6 & 9 & 12 \\
\hline Papila & 1 & 1.8 & 3 & 16 \\
\hline & 0.7 & 5 & 3.3 & 10 \\
\hline & 0.2 & 6.3 & 2.5 & 10.7 \\
\hline Media & 0.85 & 3.40 & 3.15 & 13.00 \\
\hline SD & 0.40 & 2.32 & 0.40 & 3.28 \\
\hline
\end{tabular}

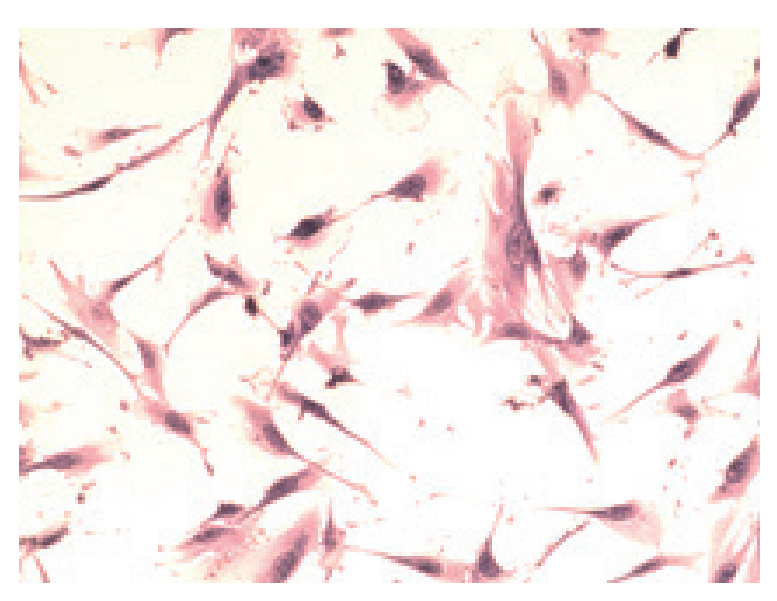

Figura 3. Imagen celular realizada por el microscopio de fase invertida, em el cual observamos células com morfologia de fibroblastos em uma de las colonias.

\section{Discusión}

La papila apical es uno de los tejidos blandos del órgano dentario, representado por tejido conjuntivo especializado presente en el ápice radicular antes del cierre de la raíz. En los dientes en desarrollo, la formación de las raíces empieza a medida que las células epiteliales del alza cervical proliferan apicalmente e influencian la diferenciación de los odontoblastos de las células mesenquimales indiferenciadas y de los cementoblastos del mesénquima folicular. ${ }^{13,14}$
Así, para la obtención de ese tejido, la recolección, tiene que realizarse cuando no haya el en el cierre total de la raíz dentaria no haya sucedido. En el caso aquí presentado presente caso, esto fue posible porque la paciente con 23 años de edad, tenía indicación de exodoncias de los terceros molares, donde estaba se observó incluso y con ápice abierto. La técnica de explant es utilizada con frecuencia en la cultura el cultivo celular, siendo una forma de obtención también para células madre de tejidos dentales, como fue demostrado en este trabajo. ${ }^{14-17}$

Con el hallazgo de células madre dentales en el año 2000 por el equipo de Gronthos et al. ${ }^{4}$ se abrió un nuevo ramo en la Odontología, ya que estas células han sido aisladas de varios tejidos humanos, incluyendo médula ósea, tejido neural y piel, convirtiendo este descubrimiento en una fuente menos invasiva y de fácil transporte. ${ }^{17}$ A pesar de ser más conocida la pulpa dental, la papila apical se ha mostrado como célula madre más embriológica al compararla con la pulpa dental de diente permanente, ya que este tejido está aún en el proceso de formación, diferenciación celular para empezar a formar la dentina radicular. ${ }^{14,16,18-20}$ No fue objetivo de este trabajo comparar las técnicas y aislamiento de los varios tejidos encontrados en el diente. El foco fue, a través de un caso clínico, observar y aislar la efectividad de la extracción celular así como su viabilidad celular. De esta forma, la obtención de las células, aislamiento y testes cinéticos tuvieron un resultado favorable lo cual lleva a pensar en teste moleculares más específicos para que en el futuro esas células puedan ser una fuente más en el tratamiento y recuperación tisular de tejidos dentales y de no dentales, como una regeneración 
de tejido óseo por ejemplo. ${ }^{14,18-20}$ Estas células formaron hueso y dentina in vivo, después de ser trasplantadas en ratones imunocomprometidos. ${ }^{18}$

Sabiendo que el concepto de las células madre define a aquellas que pueden y son capaces de auto renovarse y de diferenciarse en varias ascendencias, y sabiendo que las células madre obtenidas de tejidos dentarios también presentan potencial multifactorial, como: la alta tasa de proliferación, la capacidad multi diferenciación, fácil accesibilidad, alta viabilidad y fácil de ser inducción a ascendencias celulares distintas. Otras investigaciones con células madre han sido realizadas, su éxito y aplicabilidad en ensayos clínicos continúa siendo experimental. Debido a la heterogeneidad entre factores del paciente y de la biología de los diferentes tipos de células madre se refuerza la necesidad de un enfoque orientado e individual para la terapia con células madre. En el presente caso y comparando la literatura consultada, los estudios con células madre de la papila apical han mostrado un óptimo avance para la Odontología, por tratarse de una forma simple y fácil de obtener esas células, además de los estupendos resultados en la diferenciación en células de los tejidos óseo, cartilaginoso, adiposo y células neurales, lo que trae excelentes beneficios para la medicina y la odontología. Pero el potencial de caracterización y diferenciación de las células de la papila apical aún no están totalmente establecidos, siendo necesarias más investigaciones. Mayores conocimientos sobre aislamiento de células madre, sus nichos, así como los mecanismos moleculares de crecimiento y diferenciación celular, son necesarios, para que, de esta forma, sea posible la utilización de la terapia celular en Odontología. 2, 5,17,21

\section{Conclusión}

Fue posible obtener células madre de la papila dentaria por la técnica de explant.

Nuevas investigaciones sobre los mecanismos moleculares de generación, así como su potencial asociado a la regeneración tisular y su diferenciación entre las fuentes celulares, son necesarias, para que puedan ser utilizadas con seguridad en la clínica.

\section{Referencias bibliográficas}

1. Odorico, J. S.; Kaufman, D. S.; Thomson, J. A. Multilineage differentiation from human embryonic stem cell lines. Stem Cells, Basel, v. 19, no. 3, p. 193-204, 2001. Binaco P, Robey PG, Simmons PJ, Mesenchymal stem cells: revisting history, concepts and assays. Cell Sten Cell, 2008, 2; 313-9

2. Binaco P, Robey PG, Simmons PJ, Mesenchymal stem cells: revisting history, concepts and assays. Cell Sten Cell, 2008, 2; 313-9

3. França S. Células-tronco aumentam opções terapêuticas. Assoc Paul Cir Dent 2011; 65(2):86-89

4. Gronthos S, Mankani M, Brahim J, Robey PG, Shi S. Postnatall humam dental pulp stem cells in vitro and in vivo. Proc Natl Acad Sci USA.2000; 97 (25):13625-13630

5. Chen FM, Sun HH, Lu H, Yu Q. Stem cell-delivery therapeutics for periodontal tissue regeneration. Biomaterials, 2012; 33: 6320-6344

6. Arakaki M, Ishikawa M, Nakamura T, Iwamoto T, Yamada A,Fukumoto, E. Role of epithelial-stem cell interactions during dental cell differentiation. J Biol Chem. 2012 287: 10590-10601 
7. Mathur S, Chopra R, Pandit IK, Srivastava N, Gugnani N. Stem cell research: applicability in dentistry. Int J Oral Maxillofac Implants. 2014;29(2):210-9.

8. Morsczeck C, Gotz W, Schierholz J, Zeilhofer F, Kuhn U, Mfhl C, Sippel C, Hoffmann KH. Isolation of precursor cells (PCs) from human dental follicle of wisdom teeth. Matrix Biol. 2005; 24(2): 155-65

9. Ten Cate, Sharpe PT, Roy S, Nanci A. Ten Cate's oral histology. Development, structure, and function. 6th ed. St. Louis: Mosby; 2003 395p.

10. Bath-Balogh, M., Fehrenbach, M. J. Anatomia, histologia e embriologia dos dentes e das estruturas orofaciais. 2. ed. Barueri: Manole; 2008. Cap. 6, Desenvolvimento e erupção do dente; p. 61-91.

11. Huang GTJ, Garcia-Godoy. Missing concepts in de novo pulp regeneration J Dent Res, 2014:1-8.

12. Rai S, Kaur M, Kaur S. Applications of Stem Cells in Interdisciplinary. Dentistry and Beyond: An Overview. Annals of Medical and Health Sciences Research, 2013; 3 (2): 245-254

13. R. D'Souza. Development of the pulpodentin complex H.E. Goodis (Ed.), Seltzer and Bender's Dental Pulp, Quintessence Publishing Co, Inc, Carol Stream, IL (2002) 512p

14. Sonoyama W, Liu Y., Yamaza T., Tuan, R.S.; Wang S., Shi S., Huang GT., Characterization of the apical papilla and its residing stem cells from human immature permanent teeth: a pilot study. J Endod, 2008. 34 (2): $166-71$.

15. Lei G, Yan M, Wang Z, Yu Y, Tang C, Wang Z, Yu J, Zhang G. Dentinogenic capacity: immature root papila stem cells versus mature root pulp stem. Biol Cell,2011; 103(4):185 -96.

16. Sonoyama W, Liu Y, Fang D, Yamaza T, Seo BM, Zhang C, Liu H, Gronthos S, Wang CY, Wang S, Shi S. Mesenchymal stem cell-mediated functional tooth regeneration in swine. PLoS One. 2006 Dec 20;1:e79: $1-9$

17. Rezende KM, Bönecker M, Perez CA, Mantesso,A. Synchrotron radiation X-ray micro-fluorescence: Protocol to study mesenchymal stem cells. Microsc Res Tech. 2016; 79: 149-154.

18. Abe S, Yamaguchi S, Watanabe A, Hamada K, Amagasa T. Hard tissue regeneration capacity of apical pulp derived cells (APDCs) from human tooth with immature apex. Biochem Biophys Res Commun,2008. $371(1): 90-3$.

19. Huang GTJ, Sonoyama W, Liu Y, Liu H, Wang S,Shi S. The hidden treasure in apical papilla: Thepotential role in pulp/dentin regeneration and bioroot engineering. J. Endodont 2008; 34(6):645-651.

20. TziafasD, Kodonas K. Differntiation potencial of dental papilla, dental pulp, and apical papilla progenitor cells. J Endod, 2010. 36 (5)781-9.

21. Rezende KM, Imparato JCP, Franca DCO, Rocha MO, Bonecker M. . Dental pulp stem cells from neonatal teeth: isolation and morphological study. J Clin Diag Res. 2018; 12,: ZC46-ZC49.

Recibido: 10/06/2019

Aceptado: 14/10/2019

Correspondencia: Karla Mayra Rezende correo: Karla.rezende@usp.br 